\title{
Kultur Antera Hasil Persilangan Padi Lokal Beras Hitam dengan Varietas Budidaya (Fatmawati dan Inpari 13)
}

\author{
Anther Culture of Crosses Between Black Rice Landrace \\ and Cultivated Rice Varieties (Fatmawati and Inpari 13)
}

\author{
Yudia Azmi ${ }^{1}$, Bambang Sapta Purwoko ${ }^{2 *}$, Iswari Saraswati Dewi ${ }^{3}$, Muhamad Syukur ${ }^{2}$, dan Tintin Suhartini ${ }^{3}$ \\ ${ }^{1}$ Program Studi Pemuliaan dan Bioteknologi Tanaman, Sekolah Pascasarjana, Institut Pertanian Bogor \\ ${ }^{2}$ Departemen Agronomi dan Hortikultura, Fakultas Pertanian, Institut Pertanian Bogor \\ (Bogor Agricultural University), Jl. Meranti, Kampus IPB Darmaga, Bogor 16680, Indonesia \\ ${ }^{3}$ Balai Besar Penelitian dan Pengembangan Bioteknologi dan Sumberdaya Genetik Pertanian \\ Jl. Tentara Pelajar No. 3 A Bogor, Indonesia
}

Diterima 19 September 2016/Disetujui 19 April 2017

\begin{abstract}
Black rice become popular in recenr years due to health reason. So far, no modern variety has been released. Therefore development of new variety is necessary. The objective of this study was to obtain doubled haploid black rice lines with good agronomic characters through anther culture. Materials used in this experiment were $6 \mathrm{Fl}$ derived from black rice landrace (Melik) and two cultivated varieties (Inpari 13 and Fatmawati): Melik/Inpari13//Inpari13, Melik/Inpari13// Melik, Melik/ Fatmawati //Fatmawati//Fatmawati, Melik/Fatmawati//Fatmawati///Fatmawati, Melik/Fatmawati, and Melik/Fatmawati// Melik. The experiment was performed using a completely randomized design consisting of 12 replications. An experimental unit was a petri dish containing \pm 150 anthers. Results of the anther culture varied widely between crosses. Crosses Melik/ Inpari13//Melik, Melik/Fatmawati//Melik, and Melik/Inpari13//Inpari13 showed the best response on callus induction and plant regeneration compared to the other crosses. Melik / Inpari13 // Melik produced the highest number of acclimatized plants, the highest number and percentage of doubled haploid: 63 plants, 42 plants and 91.3\% respectively. The highest number of doubled haploid having black aleuron layer were obtained by Melik/Inpari13//Melik and Melik/Fatmawati// Melik.
\end{abstract}

Keywords: anther culture, black rice, doubled haploid, regeneration

\section{ABSTRAK}

Padiberas hitam menjadipopuler akhir-akhirini dikaitkan dengan manfaatuntuk kesehatan. Sejauhinibelumada varietas unggul padi beras hitam. Pengembangan varietas tersebut dipandang perlu. Tujuan penelitian ini ialah untuk mendapatkan galur padi beras hitam dengan warna aleuron berwarna hitam dan umur genjah hasil kultur antera. Bahan yang digunakan pada percobaan ini adalah antera F1 hasil persilangan padi lokal beras hitam (Melik) dengan 2 varietas budidaya (Inpari13 dan Fatmawati), yaitu: Melik/Inpari13//Inpari13, Melik/Inpari13//Melik, Melik/Fatmawati//Fatmawati//Fatmawati, Melik / Fatmawati//Fatmawati, Melik/Fatmawati dan Melik/ Fatmawati //Melik. Percobaan dilakukan menggunakan rancangan acak lengkap yang terdiri atas 12 ulangan. Satu unit percobaan merupakan satu cawan petri berisi \pm 150 antera. Hasil kultur antera padi beras hitam antara persilangan sangat bervariasi. Persilangan Melik/Inpari13//Melik, Melik/Fatmawati//Melik, dan Melik / Inparil3 //Inparil 3 memiliki respon induksi kalus dan regenerasi tanaman paling baik dibandingkan persilangan lainnya. Selain itu persilangan Melik/Inpari13//Melik menghasilkan genotipe yang dapat diaklimatisasi terbanyak, tanaman dihaploid terbanyak, dan persentase tanaman dihaploid tertinggi dibandingkan persilangan lainnya yakni berturut-turut 63 tanaman, 42 tanaman dan 91.3\%. Padi beras hitam yaitu padi dengan lapisan aleuron berwarna hitam terbanyak dihasilkan oleh persilangan Melik/Inpari13//Melik dan Melik/Fatmawati//Melik.

Kata kunci: dihaploid, kultur antera, padi beras hitam, regenerasi

* Penulis untuk korespondensi. e-mail: bspurwoko@ipb.ac.id 


\section{PENDAHULUAN}

Seiring waktu padi beras hitam semakin populer dan dikonsumsi karena mengandung antosianin yang kaya vitamin dan mineral sehingga sangat berguna bagi kesehatan tubuh (Kristamtini et al., 2012). Padi beras hitam (Oryza sativa L. indica) memiliki perikarp, aleuron dan endosperm yang berwarna merah-biru-ungu pekat, warna tersebut menunjukkan adanya kandungan antosianin (Sa'adah et al., 2013). Antosianin mempunyai kemampuan antioksidan, dan antikanker (Sutharut dan Sudarat, 2012) juga dapat memperlambat penuaan (Young et al., 2008). Pengembangan padi beras hitam saat ini memiliki kendala antara lain berdaya hasil rendah dan berumur dalam (relatif panjang) sehingga petani jarang menanamnya.

Pemuliaan padi beras hitam konvensional memerlukan waktu yang lama dan varietas baru yang dihasilkan masih terbatas. Salah satu teknik untuk percepatan pembentukan varietas baru adalah dengan menggunakan kultur antera, suatu teknik kultur in vitro yang dapat mempercepat perolehan galur murni dengan homozigositas tinggi melalui tanaman dihaploid (DH) yang dihasilkan langsung pada generasi pertama dalam waktu kurang dari setahun sehingga meningkatkan efisiensi proses seleksi pada pemuliaan tanaman. Selain itu kultur antera lebih hemat dalam biaya untuk tenaga kerja, sewa lahan, dan waktu pemulia dibandingkan dengan program pemuliaan konvensional (Dewi dan Purwoko, 2012). Kultur antera disebut juga dengan kultur haploid yang menghasilkan tanaman haploid. Tanaman haploid merupakan tanaman yang memiliki jumlah kromosom yang sama dengan kromosom gametnya atau tanaman dengan jumlah kromosom setengah jumlah kromosom somatiknya (Dewi dan Purwoko, 2011). Tanaman hasil kultur antera ini disebut tanaman dihaploid.

Penelitian ini menggunakan beberapa antera F1 hasil persilangan antara Melik, Inpari 13, dan Fatmawati. Melik adalah padi lokal beras hitam asal Bantul (Kristamtini et al., 2012). Inpari 13 adalah varietas unggul yang memiliki sifat tahan terhadap wereng batang coklat dan berumur genjah (Rozakurniati, 2011), sedangkan Fatmawati adalah varietas padi tipe baru yang berumur genjah (Abdullah et al., 2008). Tujuan penelitian ini adalah untuk mendapatkan galur padi beras hitam dengan warna aleuron berwarna hitam dan umur genjah hasil kultur antera.

\section{BAHAN DAN METODE}

Kegiatan kultur antera dilakukan di Laboratorium Kultur Jaringan, Kelompok Peneliti Biologi Sel dan Jaringan, BB Biogen, Bogor, pada bulan Juli 2014 sampai Februari 2015.

Bahan yang digunakan pada percobaan ini adalah antera F1 hasil persilangan padi beras hitam lokal (Melik) dengan 2 varietas budidaya (Inpari 13 dan Fatmawati), yaitu: $\mathrm{F}_{1} \mathrm{BC}_{1}=$ Melik/Inpari 13//Inpari $13, \mathrm{~F}_{1} \mathrm{BC}_{1}=$ Melik/ Inpari13////Melik, $\mathrm{F}_{1} \mathrm{BC}_{2}=$ Melik/Fatmawati//Fatmawati/// Fatmawati, $\mathrm{F}_{1} \mathrm{BC}_{1}=$ Melik/Fatmawati//Fatmawati, $\mathrm{F}_{1} \mathrm{BC}_{1}=$ Melik/Fatmawati//Melik, dan $\mathrm{F}_{1}=$ Melik/Fatmawati.
Media induksi kalus adalah media N6 yang diberi 2.0 mg L-1 NAA, $0.5 \mathrm{mg} \mathrm{L}^{-1}$ kinetin dan $0.1644 \mathrm{~g} \mathrm{~L}^{-1}$ putresin, sedangkan media regenerasi dan perakaran adalah media MS yang diberi NAA dan Kinetin (Dewi dan Purwoko, 2011). Jenis poliamin yang digunakan adalah Putresin 10 ${ }^{3} \mathrm{M}$ dan sukrosa yang ditambahkan pada media induksi kalus dan media regenerasi. Zat pengatur tumbuh lainnya yaitu IBA. Bahan untuk sterilisasi malai menggunakan 20\% pemutih komersial dan air steril. Bahan untuk sterilisasi alat yaitu alkohol 90\%, dan alkohol 70\%. Unsur lain yang ditambahkan yaitu phytagel TM $3 \mathrm{~g} \mathrm{~L}^{-1}$ pada $\mathrm{pH} 5.8$.

Percobaan dilakukan menggunakan rancangan acak lengkap yang terdiri atas 12 ulangan. Satu unit percobaan merupakan satu cawan petri berisi \pm 150 antera (25 buah bulir bunga (spikelet) dari satu tanaman yang berasal dari satu genotipe F1). Total satuan percobaan 72 satuan percobaan.

\section{Persiapan Eksplan}

Tanaman sumber eksplan (donor) ditanam di rumah kaca. Saat tanaman mencapai fase bunting, malai yang masih dibungkus selubung mulai dikumpulkan. Malai yang masih berada di dalam selubung setelah dicuci bersih kemudian dibungkus dengan aluminium foil yang telah dilapisi dengan kertas tisu dan disimpan dalam ruang gelap bersuhu $5{ }^{\circ} \mathrm{C}$.

\section{Sterilisasi Eksplan}

Setelah 8-10 hari, selubung malai dibuka dan malai yang berada di bagian tengah dan atas yang berwarna kuning kehijauan diambil. Malai dengan spikelet yang panjang antera dan filamennya tidak melebihi $1 / 2$ panjang spikelet dipilih untuk mendapatkan antera yang diinginkan yaitu antera yang berwarna kuning kehijauan kemudian disterilkan dengan 10-20\% pemutih komersial, yaitu larutan pemutih yang mengandung $5.24 \% \mathrm{NaOCl}$ selama 20 menit sebelum dicuci dengan air steril 2 x 5 menit di dalam laminar air flow cabinet.

\section{Inokulasi atau Penanaman Eksplan}

Spikelet yang sudah steril dipotong $1 / 3$ dari pangkalnya dan dikumpulkan pada cawan petri steril. Dengan menggunakan pinset, masing-masing spikelet kemudian diketukkan pada tepi cawan petri $100 \mathrm{~mm} \times 15$ $\mathrm{mm}$ yang sudah berisi $25 \mathrm{~mL}$ media induksi kalus sampai ke 6 antera keluar sehingga diperkirakan 150 antera per cawan petri ( \pm 25 spikelet). Inokulasi atau penanaman eksplan ini dilakukan dalam laminar air flow cabinet dan diinkubasi di ruang gelap bersuhu $25 \pm 2{ }^{\circ} \mathrm{C}$ untuk mempercepat keluarnya kalus yang berasal dari butir sari di dalam antera.

\section{Regenerasi Tanaman dari Kalus}

Pada umur 3-8 minggu kalus mulai terbentuk dan dipindahkan ke dalam botol kultur yang sudah berisi $25 \mathrm{~mL}$ media regenerasi. 


\section{Aklimatisasi}

Tanaman hijau yang tumbuh dari kalus pada media regenerasi dan sudah mencapai tinggi 3-5 cm dipindahkan ke dalam tabung kultur berisi $15 \mathrm{~mL}$ media perakaran. Setelah akar tumbuh, tanaman sudah siap diaklimatisasi (Dewi dan Purwoko, 2011).

Pengamatan dilakukan terhadap jumlah kalus yang terbentuk, jumlah kalus yang menghasilkan tanaman, lamanya inisiasi kalus, jumlah tanaman hijau, jumlah tanaman albino, jumlah antera yang ditanam, dan jumlah tanaman dihaploid yang dihasilkan. Data primer digunakan untuk mengetahui persentase tanaman hijau, persentase tanaman albino, persentase jumlah kalus terhadap jumlah antera (efisiensi pembentukan kalus), dan jumlah tanaman hijau terhadap jumlah antera (efisiensi pembentukan tanaman hijau). Data dianalisis menggunakan analisis ragam dan dilanjutkan dengan uji DMRT pada taraf 5\% bila terdapat pengaruh pada perlakuan.

\section{HASIL DAN PEMBAHASAN}

Hasil yang diperoleh pada penelitian ini menunjukkan bahwa respon F1 semua hasil persilangan padi lokal beras hitam dengan 2 varietas budidaya terhadap jumlah antera, inisiasi kalus, jumlah kalus, jumlah kalus menghasilkan tanaman, jumlah kalus menghasilkan tanaman hijau, jumlah kalus menghasilkan tanaman albino, tanaman total, tanaman hijau, dan tanaman albino berbeda nyata (Tabel 1). Dapat disimpulkan bahwa terdapat keragaman respon terhadap kultur antera yang sangat tinggi pada F1 hasil persilangan padi beras hitam lokal dengan 2 varietas budidaya. Sejalan dengan penelitian Bagheri and Jelodar (2008) yang mendapatkan hasil respon genotipe sangat nyata pada induksi kalus kultur antera padi lokal Iran dan galur padi komersial serta F1 hasil persilangannya.

\section{Induksi Pembentukan Kalus dan Regenerasi Tanaman}

Pembentukankalus enampersilangan padakulturantera padi lokal beras hitam dengan varietas budiaya memiliki waktu yang berbeda-beda yakni lebih dari 3 minggu (2734 hari) (Tabel 2). Kultur antera padi subspesies japonica, kalus terbentuk setelah 3 minggu (Dewi et al., 2004; Dewi dan Purwoko, 2008; Dewi dan Purwoko, 2011). Umur kalus yaitu lamanya waktu (hari) sejak kalus diinduksi sampai kalus disubkultur ke media regenerasi sangat menentukan frekuensi regenerasi (Dewi dan Purwoko, 2011). Padi beras hitam menghasilkan jumlah kalus yang berbeda-beda pada masing-masing persilangan. Peningkatan produksi kalus

Tabel 1. Hasil sidik ragam peubah kultur antera hasil persilangan padi lokal beras hitam dengan varietas budidaya

\begin{tabular}{|c|c|c|c|c|c|c|c|c|c|}
\hline \multirow{2}{*}{ Sidik ragam } & \multicolumn{9}{|c|}{ Peubah } \\
\hline & JA & IK & $\mathrm{JK}^{+}$ & $\mathrm{JKMT}^{+}$ & $\mathrm{JKTH}^{+}$ & $\mathrm{JKTA}^{+}$ & $\mathrm{TT}^{+}$ & $\mathrm{TH}^{+}$ & $\mathrm{TA}^{+}$ \\
\hline Kuadrat tengah & 37.1 & 86.3 & 51.4 & 0.7 & 0.3 & 0.3 & 5.0 & 2.8 & 1.6 \\
\hline F hitung & $2.4^{*}$ & $2.4^{*}$ & $16.8^{* *}$ & $3.4^{* *}$ & $9.4^{* *}$ & $2.2 *$ & $3.9 * *$ & $6.0 * *$ & $2.3^{*}$ \\
\hline
\end{tabular}

Keterangan: $\mathrm{JA}=$ jumlah antera; $\mathrm{IK}=$ inisiasi kalus; $\mathrm{JK}=$ jumlah kalus; JKMT $=$ jumlah kalus yang menghasilkan tanaman (hijau dan albino); JKTH = jumlah kalus yang menghasilkan tanaman hijau; JKTA = jumlah kalus yang menghasilkan tanaman albino; $\mathrm{TT}=$ tanaman hijau+albino; $\mathrm{TH}=$ tanaman hijau; $\mathrm{TA}=$ tanaman albino $;{ }^{+}=$data ditransformasi dengan metode transformasi akar; ** = berbeda sangat nyata pada taraf $\alpha=1 \% ; *=$ berbeda nyata pada taraf $\alpha=5 \%$

Tabel 2. Hasil induksi kalus pada kultur antera enam persilangan padi lokal beras hitam dengan varietas budidaya

\begin{tabular}{|c|c|c|c|c|c|c|c|c|}
\hline Persilangan & JK & $\begin{array}{l}\text { IK } \\
\text { (hari) }\end{array}$ & JKMT & JKTH & JKTA & $\begin{array}{c}\text { Persentase } \\
\text { KTMT } \\
(\%)\end{array}$ & $\begin{array}{c}\text { Persentase } \\
\text { KTH } \\
(\%)\end{array}$ & $\begin{array}{c}\text { Persentase } \\
\text { KTA } \\
(\%)\end{array}$ \\
\hline Melik/Inpari13//Inpari13 & $10.0 \mathrm{~d}$ & $34.3 \mathrm{a}$ & $1.7 \mathrm{c}$ & $1.4 \mathrm{~b}$ & $0.3 b$ & 83.0 & 14.0 & 3.0 \\
\hline Melik/Inpari13//Melik & $48.2 \mathrm{c}$ & $29.5 \mathrm{ab}$ & $4.7 \mathrm{a}$ & $2.4 \mathrm{a}$ & $2.3 \mathrm{a}$ & 90.2 & 5.0 & 4.8 \\
\hline $\begin{array}{l}\text { Melik/Fatmawati// } \\
\text { Fatmawati///Fatmawati }\end{array}$ & $54.8 \mathrm{bc}$ & $30.7 \mathrm{ab}$ & $2.1 \mathrm{bc}$ & $0.2 \mathrm{c}$ & $1.9 \mathrm{a}$ & 96.1 & 0.4 & 3.5 \\
\hline $\begin{array}{l}\text { Melik/Fatmawati// } \\
\text { Fatmawati }\end{array}$ & $61.0 \mathrm{bc}$ & $28.9 \mathrm{ab}$ & $3.2 \mathrm{abc}$ & $1.4 \mathrm{~b}$ & $1.8 \mathrm{a}$ & 94.7 & 2.3 & 3.0 \\
\hline Melik/Fatmawati//Melik & $87.0 \mathrm{a}$ & $26.5 b$ & $2.8 \mathrm{bc}$ & $1.3 \mathrm{~b}$ & $1.5 \mathrm{ab}$ & 96.8 & 1.5 & 1.7 \\
\hline Melik/Fatmawati & $77.0 \mathrm{ab}$ & $27.8 b$ & $3.7 \mathrm{ab}$ & $1.4 \mathrm{~b}$ & $2.3 \mathrm{a}$ & 95.2 & 1.8 & 3.0 \\
\hline
\end{tabular}

Keterangan: JK = jumlah kalus; IK = Inisiasi kalus ; JKMT = jumlah kalus yang menghasilkan tanaman (hijau dan albino); JKTH = jumlah kalus yang menghasilkan tanaman hijau; JKTA = jumlah kalus yang menghasilkan tanaman albino; KTMT = persentase kalus tidak menghasilkan tanaman hijau dan albino; $\mathrm{KTH}=$ persentase kalus yang menghasilkan tanaman hijau; KTA = persentase kalus menghasilkan tanaman albino. Angka dalam satu kolom yang diikuti oleh huruf yang sama tidak berbeda nyata pada uji DMRT pada taraf $\alpha 5 \%$ 
sangat penting karena peluang untuk mendapatkan tanaman hijau akan lebih besar (Dewi et al., 2007).

Rataan jumlah kalus menghasilkan tanaman berbedabeda pada setiap persilangan kultur antera padi lokal beras hitam dengan varietas budidaya. Rataan jumlah kalus menghasilkan tanaman (hijau dan albino) paling banyak (4.7 butir kalus) dihasilkan pada persilangan Melik/Inpari13// Melik. Jumlah kalus yang bervariasi tergantung dari daya tanggap mikrospora dalam antera yang dikulturkan (Dewi et al., 2009). Rataan kalus yang beregenerasi menjadi tanaman albino lebih banyak dibandingkan rataan kalus yang beregenerasi menjadi tanaman hijau. Menurut Safitri et al. (2010) yang menggunakan formulasi media kultur antera yang sama bahwa kemampuan membentuk kalus pada kultur antera persilangan tidak diimbangi dengan kemampuan meregenerasikan kalus menjadi tanaman, khususnya tanaman hijau.

Berdasarkan persentase kalus menghasilkan tanaman hijau dan tanaman albino, diperoleh persentase kalus tidak menghasilkan tanaman masing-masing persilangan padi beras hitam dengan varietas budidaya. Persilangan dengan Melik (indica) menghasilkan daya kultur antera lebih rendah dibandingkan dengan varietas budidaya (japonica). Tetua japonica dan indica menghasilkan daya kultur antera lebih tinggi dibandingkan F1 yang hanya melibatkan tetua indica saja (Grewal et al., 2011: Gunarsih, 2015). Umumnya persilangan dengan Fatmawati menghasilkan tanaman hijau dan tanaman albino lebih banyak dibandingkan persilangan lainnya. Hal ini sejalan dengan penelitian Safitri et al. (2010) yang menggunakan varietas Fatmawati sebagai tetua persilangan pada kultur antera persilangan Fatmawati/Fulan Telo Gawa dan resiprokalnya.

Persilangan Melik/Inpari13//Melik mempunyai daya kultur antera yang cukup tinggi dibandingkan persilangan lainnya. Hal ini terlihat dari jumlah tanaman hijau, tanaman albino, dan jumlah tanaman total (hijau dan albino) lebih banyak dihasilkan yakni sebesar 8.7 tanaman, 7.8 tanaman, dan 16.5 tanaman dibandingkan persilangan lainnya (Tabel 3). Banyaknya tanaman hijau yang dihasilkan selalu diiringi dengan banyaknya tanaman albino (Safitri et al., 2010). Namun yang terpenting adalah peningkatan regenerasi tanaman hijau karena akan mempercepat atau memperbesar kemungkinan bagi pemulia tanaman untuk memperoleh galur yang diinginkan (Herawati et al., 2008).

Induksi kalus dan regenerasi tanaman dipengaruhi terutama oleh kondisi kultur (kondisi suhu di ruang kultur, intensitas cahaya dan kondisi ruang gelap) walaupun keduanya ada di bawah kontrol genetik. Frekuensi induksi kalus dan pembentukan tanaman hijau dikendalikan oleh banyak gen (gen minor/poligenik) sehingga gen tanaman donor mempunyai peran penting dalam menentukan frekuensi produksi tanaman dalam kultur antera (Dewi et al., 2007; Asakaviciute, 2008) juga penyesuaian kondisi sebelum dan setelah kultur antera (Cha-Um et al., 2009).

\section{Efisiensi Pembentukan Kalus dan Tanaman Hijau}

Efisiensi pembentukan kalus setiap persilangan berbeda-beda (Tabel 4). Efisiensi pembentukan kalus dihitung berdasarkan jumlah kalus yang terbentuk pada jumlah antera yang ditanam. Menurut Zhang (1992), efisiensi kultur antera terkait dengan produksi tanaman hijau yang dinyatakan dalam rasio tanaman hijau terhadap jumlah kalus menghasilkan tanaman dan efisiensi tanaman hijau terhadap jumlah antera yang ditanam merupakan kriteria terpenting dalam memperhitungkan efisiensi penggunaan kultur antera. Persilangan Melik/Inpari13//Inpari13 dan Melik/Inpari13//Melik memiliki efisiensi kultur antera lebih baik dibandingkan persilangan lainnya karena memiliki rasio atau perbandingan tanaman hijau terhadap kalus menghasilkan tanaman dan efisiensi tanaman hijau terhadap jumlah antera tertinggi.

\section{Aklimatisasi dan Tanaman Dihaploid}

Hasil aklimatisasi tanaman menunjukkan bahwa persilangan Melik/Inpari13//Melik menghasilkan tanaman yang dapat diaklimatisasi terbanyak, tanaman dihaploid terbanyak, dan persentase tanaman dihaploid tertinggi dibandingkan persilangan lainnya yakni berturut-turut 63 tanaman, 42 tanaman, dan 91.3\%. Sementara jumlah tanaman hidup terbanyak pada persilangan Melik/Fatmawati// Fatmawati sebanyak 49 tanaman diikuti persilangan Melik/ Inpari13//Melik sebanyak 46 tanaman (Tabel 5). Hal ini sejalan dengan penelitian Herawati et al. (2008) bahwa semakin banyak tanaman hijau yang dihasilkan maka

Tabel 3. Regenerasi tanaman pada kultur antera enam persilangan padi lokal beras hitam dengan varietas budidaya

\begin{tabular}{lccccc}
\hline Persilangan & $\begin{array}{c}\text { Tanaman } \\
\text { hijau }\end{array}$ & $\begin{array}{c}\text { Tanaman } \\
\text { albino }\end{array}$ & $\begin{array}{c}\text { Tanaman } \\
\text { hijau+albino }\end{array}$ & $\begin{array}{c}\text { Persentase } \\
\text { tanaman } \\
\text { hijau (\%) }\end{array}$ & $\begin{array}{c}\text { Persentase } \\
\text { tanaman } \\
\text { albino (\%) }\end{array}$ \\
\hline Melik/Inpari13//Inpari13 & $6.1 \mathrm{ab}$ & $1.1 \mathrm{~b}$ & $7.2 \mathrm{~b}$ & 84.72 & 15.28 \\
Melik/Inpari13//Melik & $8.7 \mathrm{a}$ & $7.8 \mathrm{a}$ & $16.5 \mathrm{a}$ & 52.73 & 47.27 \\
Melik/Fatmawati//Fatmawati//Fatmawati & $0.4 \mathrm{c}$ & $4.0 \mathrm{ab}$ & $4.4 \mathrm{c}$ & 9.09 & 90.91 \\
Melik/Fatmawati//Fatmawati & $5.8 \mathrm{ab}$ & $3.5 \mathrm{ab}$ & $9.3 \mathrm{~b}$ & 62.37 & 37.63 \\
Melik/Fatmawati//Melik & $4.5 \mathrm{ab}$ & $4.8 \mathrm{ab}$ & $9.3 \mathrm{~b}$ & 48.39 & 51.61 \\
Melik/Fatmawati & $4.2 \mathrm{~b}$ & $4.8 \mathrm{ab}$ & $9.0 \mathrm{~b}$ & 46.67 & 53.33 \\
\hline
\end{tabular}

Keterangan: Angka dalam satu kolom yang diikuti oleh huruf yang sama tidak berbeda nyata pada uji DMRT pada taraf $\alpha 5 \%$ 
Tabel 4. Efisiensi pembentukan kalus dan tanaman hijau pada kultur antera hasil persilangan padi lokal beras hitam dengan varietas budidaya

\begin{tabular}{lcccc}
\hline Persilangan & $\begin{array}{c}\text { Jumlah antera } \\
\text { (butir) }\end{array}$ & $\begin{array}{c}\text { Efisiensi } \\
\text { pembentukan } \\
\text { kalus (\%) }\end{array}$ & $\begin{array}{c}\text { Rasio } \\
\text { TH:JKMT }\end{array}$ & $\begin{array}{c}\text { EPTH } \\
(\%)\end{array}$ \\
\hline Melik/Inpari13//npari13 & 146.4 & 6.8 & 3.6 & 4.2 \\
Melik/Inpari13//Melik & 149.7 & 32.2 & 1.9 & 5.8 \\
Melik/Fatmawati//Fatmawati//Fatmawati & 146.8 & 37.3 & 0.2 & 0.3 \\
Melik/Fatmawati//Fatmawati & 144.6 & 42.2 & 1.8 & 4.0 \\
Melik/Fatmawati//Melik & 145.3 & 59.9 & 1.6 & 3.1 \\
Melik/Fatmawati & 147.2 & 52.3 & 1.1 & 2.9 \\
\hline
\end{tabular}

Keterangan: JA= jumlah antera; EPK = efisiensi pembentukan kalus; TH:JKMT = rasio tanaman hijau:JKMT; EPTH=efisiensi pembentukan tanaman hijau

semakin banyak kemungkinan mendapatkan galur dihaploid (DH), galur dihaploid yang mempunyai homozigositas tinggi akan memudahkan seleksi selanjutnya.

Keberhasilan kultur antera dipengaruhi antara lain status fisiologi tanaman donor. Tanaman padi yang ditanam pada musim hujan menyebabkan antera lebih sulit dikulturkan karena banyak yang menempel dan berair, sedangkan tanaman padi yang ditanam saat intensitas hujan rendah lebih mudah untuk dikulturkan. Hal lain yang perlu diperhatikan ialah kondisi suhu di ruang kultur, intensitas cahaya dan kondisi ruang gelap untuk induksi kalus serta ruang terang untuk regenerasi tanaman. Suhu $27{ }^{\circ} \mathrm{C}$ mempengaruhi perkembangan mikrospora ke tahap uninukleat dan tahap binukleat dapat berlangsung cepat atau lambat (Dewi dan Purwoko, 2011).

Tanaman dihaploid hasil kultur antera padi beras hitam menunjukkan bahwa padi beras hitam yaitu padi dengan lapisan aleuron berwarna hitam terbanyak dihasilkan pada persilangan Melik/Inpari13//Melik dan Melik/ Fatmawati//Melik (Tabel 6). Warna aleuron F1 ternyata

Tabel 5. Hasil aklimatisasi dan tanaman dihaploid pada kultur antera hasil persilangan padi lokal beras hitam dengan varietas budidaya

\begin{tabular}{lccccc}
\hline \multirow{2}{*}{ Persilangan } & \multicolumn{5}{c}{ Jumlah tanaman hijau } \\
\cline { 2 - 6 } & Aklimatisasi & Hidup & Hidup (\%) & Dihaploid & Dihaploid (\%) \\
\hline Melik/Inpari13//Inpari13 & 37 & 23 & 62.2 & 8 & 34.8 \\
Melik/Inpari13//Melik & 63 & 46 & 73.0 & 42 & 91.3 \\
Melik/Fatmawati//Fatmawati//Fatmawati & 2 & 2 & 100.0 & 1 & 50.0 \\
Melik/Fatmawati//Fatmawati & 50 & 49 & 98.0 & 28 & 57.1 \\
Melik/Fatmawati//Melik & 38 & 29 & 76.3 & 17 & 58.6 \\
Melik/Fatmawati & 39 & 36 & 92.3 & 8 & 22.2 \\
\hline
\end{tabular}

Tabel 6. Warna aleuron tanaman dihaploid $\left(\mathrm{DH}_{0}\right)$ hasil kultur antera hasil persilangan padi lokal beras hitam dengan varietas budidaya

\begin{tabular}{lcc}
\hline \multirow{2}{*}{ Persilangan } & \multicolumn{3}{c}{ Warna aleuron } & Putih \\
\cline { 2 - 4 } Melik/Inpari13//Inpari13 & Hitam & 2 \\
Melik/Inpari13//Melik & 6 & 14 \\
Melik/Fatmawati//Fatmawati//Fatmawati & 28 & 1 \\
Melik/Fatmawati//Fatmawati & 0 & 24 \\
Melik/Fatmawati//Melik & 4 & 10 \\
Melik/Fatmawati & 7 & 3 \\
\hline
\end{tabular}


sama dengan warna aleuron tetua betina yang digunakan pada persilangannya sehingga diduga terdapat pengaruh maternal (maternal effect) untuk karakter warna aleuron. Hal ini sejalan dengan penelitian Safitri et al. (2010) yang memperoleh semua persilangan yang menggunakan Fulan Telo Mihat sebagai tetua menghasilkan keturunan F1 yang mempunyai warna merah.

Widyawati et al. (2013) mengemukakan bahwa warna aleuron merupakan penentu kandungan antosianin. Padi beras hitam yaitu padi dengan aleuron padi beras berwarna hitam mempunyai kandungan antosianin paling tinggi karena intensitas warna aleuron hitam dihasilkan sangat tinggi. Kristamtini et al. (2014) melaporkan bahwa warna aleuron beras hitam dari hitam cerah sampai hitam pekat.

\section{KESIMPULAN}

Persilangan silang balik Melik/Inpari13//Melik, Melik/Fatmawati//Melik, dan Melik/Inpari13//Inpari13 memiliki respon induksi kalus dan regenerasi tanaman paling baik dibandingkan persilangan lainnya. Persilangan Melik/Inpari13//Melik menghasilkan tanaman yang dapat diaklimatisasi terbanyak, tanaman dihaploid terbanyak, dan persentase tanaman dihaploid tertinggi dibandingkan persilangan lainnya yakni berturut-turut 63 tanaman, 42 tanaman dan $91.3 \%$. Padi beras hitam yaitu padi dengan lapisan aleuron berwarna hitam terbanyak dihasilkan pada persilangan Melik/Inpari13//Melik dan Melik/Fatmawati// Melik.

\section{UCAPAN TERIMA KASIH}

Ucapan terima kasih penulis sampaikan kepada Staf Balai Besar Penelitian dan Pengembangan Bioteknologi dan Sumberdaya Genetik Pertanian (BB Biogen) yang telah membantu pelaksanaan penelitian.

\section{DAFTAR PUSTAKA}

Abdullah, B., Dewi, I.S., Sularjo, Safitri, H., Lestari, A.P. 2008. Perakitan padi tipe baru melalui seleksi silang berulang dan kultur antera. Penelitian Pertanian Tanaman Pangan. 27:1-8.

Asakaviciute, R. 2008. Androgenesis in anther culture of lithuanian spring barley (Hordeum vulgare L.) and potato (Solanum tuberosum L.) cultivars. Turk. J. Biol. 32:155-160.

Bagheri, N., N.B. Jelodar. 2008. Combining ability and heritability of callus induction and green-plant regeneration in rice anther culture. Biotechnology $7: 287-292$

Cha-Um, S., B. Srianan, A. Pichakum, C. Kirdmanee. 2009. An efficient procedure for embryogenic callus induction and dihaploid plant regeneration through anther culture of Thai aromatic rice (Oryza sativa L. subsp indica). In Vitro Cell. Dev. Biol. Plant 45:171179.

Dewi, I.S., B.S. Purwoko, H. Aswidinnoor, I.H. Somantri. 2004. Kultur antera padi pada beberapa formulasi media yang mengandung poliamin. Bioteknologi Pertanian 9:14-19.

Dewi, I.S., B.S. Purwoko, H. Aswidinnoor, I.H. Somantri. 2007. Regenerasi tanaman pada kultur antera padi: pengaruh persilangan dan aplikasi putresin. Bul. Agron. 35:68-74.

Dewi, I.S., B.S. Purwoko. 2008. Role of polyamines in inhibition of ethylene biosynthesis and their effects on rice anther culture development. IJAS. 9:60-67.

Dewi, I.S., B.S. Purwoko, H. Aswidinnoor, I.H. Somantri, M.A. Chozin. 2009. Plant regeneration from anther culture of several genotypes of indica rice tolerant to aluminum toxicity. Indonesian J. Agric. 2:1-5.

Dewi, I.S., B.S. Purwoko. 2011. Kultur in vitro untuk pembentukan tanaman haploid androgenik. Dalam G.A. Wattimena, N. Ansori, N.M.A. Wiendi, A. Purwito, D. Efendi, B.S, Purwoko, N. Khumaida. Bioteknologi dalam Pemuliaan Tanaman. IPB Press, Bogor.

Dewi, I.S., B.S. Purwoko. 2012. Kultur antera untuk percepatan perakitan varietas padi di Indonesia. AgroBiogen. 8:78-88.

Grewal, D., C. Manito, V. Bartolome. 2011. Doubled haploids generated through anther culture from crosses of elite indica and japonica cultivars and/ or lines of rice: large-scale production, agronomic performance, and molecular characterization. Crop Sci. 51:2544-2553.

Gunarsih, C. 2015. Pembentukan galur-galur dihaploid padi sawah tadah hujan toleran kekeringan melalui kultur antera. Tesis. Sekolah Pascasarjana. Institut Pertanian Bogor. Bogor.

Herawati, R., B.S. Purwoko, N. Khumaida, I.S. Dewi, Abdullah. 2008. Pembentukan galur haploid ganda padi gogo dengan sifat-sifat tipe baru melalui kultur antera. Bul. Agron. 36:181-187.

Kristamtini, Taryono, P. Basunanda, R.H. Murti, Supriyanta, S. Widyayanti, Sutarno. 2012. Morphological of genetic relationships among black rice landraces from Yogyakarta and surrounding areas. ARPN J. Agric. Biol. Sci. 7:982-989. 
Kristamtini, Taryono, P. Basunanda, R.H. Murti. 2014. Keragaman genetik dan korelasi parameter warna beras dan kandungan antosianin total sebelas kultivar padi beras hitam lokal. Ilmu Pertanian. 17:57-70.

Safitri, H., B.S. Purwoko, D. Wirnas, I.S. Dewi, B. Abdullah. 2010. Daya kultur antera beberapa persilangan padi gogo dan padi tipe baru. J. Agron. Indonesia 38:8187.

Sa'adah, I.R., Supriyanta, Subejo. 2013. Keragaman warna gabah dan warna beras varietas lokal padi beras hitam (Oryza sativa L.) yang dibudidayakan oleh petani Kabupaten Sleman, Bantul dan Magelang. Vegetalika 2:13-20.

Sutharut, J., J. Sudarat. 2012. Total anthocyanin content and antioxidant activity of germinated colored rice. Internat. Food Res. J. 19:215-221.
Widyawati, P.S., T.I.P. Suseno, A.M. Sutedja. 2013. Perbedaan sifat fisikokimia, sensori, dan aktifitas antioksidan beras organik lokal. Dalam Seminar Nasional Insentif Riset Sinas Membangun Sinergi Riset Nasional Untuk Kemandirian Teknologi. Jakarta.

Young, P.S., K.S. Joong, C.H. Ihl. 2008. Isolation of anthocyani from black rice and screening of its antioxidant activities. Korean J. Microbiol. Biotechnol. 36:55-60.

Zhang, Z.H. 1992. Anther culture for rice breeding at SAAS. p. 38-74. In Zheng, K., T. Murashige (Eds.). Anther Culture for Rice Breeders. Proceedings of Seminar and Training for Rice Anther Culture at Hangzhou, China. 